\title{
Unsaponifiable Fraction of Unripe Fruits of Olea europaea: An Interesting Source of Anti-inflammatory Constituents
}

Authors

Affiliations
Fabrizio Gelmini ${ }^{1}$, Massimiliano Ruscica ${ }^{2}$, Chiara Macchi ${ }^{2}$, Viviana Bianchi ${ }^{1}$, Roberto Maffei Facino ${ }^{1}$, Giangiacomo Beretta ${ }^{1}$, Paolo Magni ${ }^{2}$

${ }^{1}$ Department of Pharmaceutical Sciences, Università degli Studi di Milano, Milan, Italy

${ }^{2}$ Department of Pharmacological and Biomolecular Sciences, Università degli Studi di Milano, Milan, Italy
Key words

- Olea europaea

- Oleaceae

- unsaponifiable fraction

- triterpenoids-sterol compounds

- unripe olive oil

- osteoarthrosis

- topical application

- inflammation received January 22, 2015 accepted Sept. 12, 2015

\section{Bibliography}

DOI http://dx.doi.org/

10.1055/s-0035-1558155

Published online November 6,

2015

Planta Med 2016; 82: 273-278

(c) Georg Thieme Verlag KG

Stuttgart · New York .

ISSN 0032-0943

\section{Correspondence}

\section{Paolo Magni, MD, PhD}

Department of Pharmacological and Biomolecular Sciences

Università degli Studi di Milano

Via Balzaretti 9

20133 Milan

Italy

Phone: + 390250318229

Fax: + 390250318204

paolo.magni@unimi.it

\section{Abstract}

$\nabla$

The unsaponifiable fraction of olive oil from unripe fruits of Olea europaea at different stages of maturation (from 20 to 32 weeks after flowering) was analyzed by gas chromatography-mass spectrometry in order to select the time associated to the unsaponifiable fraction with the maximal yield in bioactive constituents. According to quantitative gas chromatography-mass spectrometry analysis, the unsaponifiable fraction ( $2.46 \%$ of the total oil) from olive fruits at the 22nd week was found to contain the maximal yield in anti-inflammatory constituents. Its composition was lanosterol $(2.60 \mathrm{mg} / \mathrm{g}$ oil $)$, stigmasterol (2.15), cycloartanol acetate (2.04), stigma-

\section{Introduction}

$\nabla$

Olive oil is a functional food from Olea europaea $\mathrm{L}$. (Oleaceae), which, in quantitative terms, can be classified into two fractions: the major one, composed of tryglycerol compounds (TAGs, 97-98\%), of which $60-85 \%$ are esterified with monounsaturated fatty acids (MUFA), and the remainding one, accounting for $3-21 \%$, containing polyunsaturated fatty acids (PUFA). The second fraction comprises minor components of virgin olive oil $(1-2 \%)$ made up of the unsaponifiable fraction (UF), whose molecular structures are extractable by the solvent after saponification of the oil (hydrocarbons, tocopherols, fatty alcohol, triterpenic derivatives, phytosterols, etc.).

It is widely believed that the anti-inflammatory minor components of the UF concur with phenolics in the oil matrix (tyrosol, hydroxytyrosol, oleorupein, gallic, cumaric, and caffeic acids) in preventing the onset and propagation of inflammatory processes at different sites, including the vascular endothelium, whose dysfunction leads to cardiovascular disease in humans. However, stan-3,5-diene (2.01), obtusifoliol (1.93), cholesta-4,6-dien-3-one (1.42), $\alpha$-amyrin (1.42), $\alpha$-tocopherol (1.32), squalene (1.02), $\beta$-amyrin (0.57), and $\beta$-sitosterol (0.22). At later times, there was a decrease in the quantitative unsaponifiable fraction yield and a qualitative shift in the bioactive constituents. The 22nd week unsaponifiable fraction was subsequently incorporated into a topical preparation to be utilized for a small pilot clinical study in five patients affected by osteoarthrosis. According to clinical observation, the application of the ointment (three times daily for three weeks) attenuated hand and knee joint inflammatory features in all patients and was not associated to any adverse reactions.

the qualitative and quantitative composition of bioactive constituents of olive fruits, including those present in the UF, appears quite variable during their development and may depend upon the specific stage of maturation [1], thus resulting in a variable anti-inflammatory activity. In consideration of such composition variability, the first aim of the study was to isolate and qualitatively characterize the UFs present in the oil samples obtained from drupes harvested at different stages (20-32 weeks after flowering; WAF) of maturation. The aim was to define the period that would give an oil containing a UF with the highest yield of anti-inflammatory constituents (sterols, triterpenoids, squalene, etc.). The second aim of the study was to quantitatively define the constituents of the UF isolated from the oil of the period of interest.

This olive oil fraction has never been evaluated for the treatment of chronic inflammatory disorders such as osteoarthritis (OA), which shares several inflammatory and immunological pathways with cardiovascular disease [2]. The phytotherapeutic approach with herbal medicinal products for the 


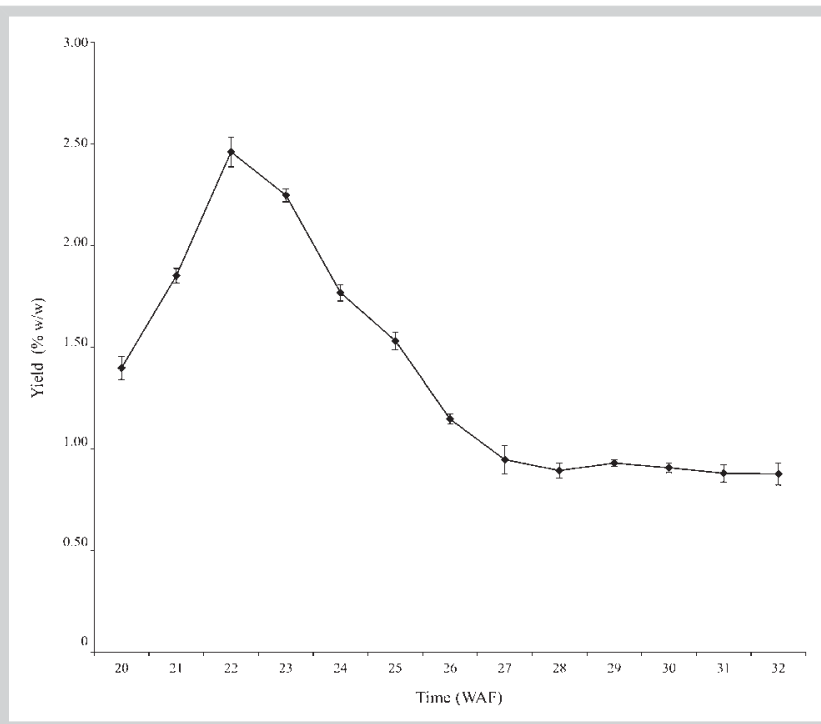

Fig. 1 Quantitative profile (\% content $w / w$ ) of the UFs from unripe fruits at different stages of maturation. Time is reported as weeks after flowering (WAF). Data are mean \pm SD $(S D<10 \%), n=3$.

management of $\mathrm{OA}$ is still in its infancy. In any case, complementary and alternative medicine has been proposed as a substitute and/or a complement to conventional therapies [3]. Dietary supplements containing $\omega-3$ fatty acids achieve worthwhile improvement and phytoextracts containing boswellic acid, curcumin, devil's claw, capsaicin, andrographolide [from Andrographis paniculata (Burm.f.) Wall. ex Nees (Acanthaceae)] as such or as herbal mixtures have given promising results for OA treatment, with no adverse reactions [4]. In light of these observations and of recent in vitro and in vivo data demonstrating the anti-inflammatory efficacy of the UFs from some other oils, such as Awara pulp from Astrocaryum vulgare M. (Arecaceae) [5], Oenothera biennis L. (Onagraceae) [6], and Cucurbita maxima Duchesne (Cucurbitaceae) [7], the present research project also included a small pilot study designed to investigate whether the anti-inflammatory constituents of the UF of olive oil, after suitable formulation in an ointment, may relief of joint inflammatory symptoms in a small group of OA patients.

\section{Results}

$\nabla$

The quantitative profile of the yield of the UFs from the oils from unripe fruits harvested at different stages of maturation from 20 to $32 \mathrm{WAF}$ is shown in $\odot$ Fig. 1. Compared to extra virgin oil from mature fruits, containing about $0.5 \% \mathrm{UF}$, the oil from unripe fruits showed a greater UF content already at $20 \mathrm{WAF}$ (about a 3-fold increase), with a further increase at subsequent times, peaking at 22 WAF [a 5 -fold increase, corresponding to $2.46 \%$ of the total oil $(\mathrm{w} / \mathrm{w})]$. The UF content decreased thereafter, progressively falling to $0.88 \%$ of the total oil when the olives were nearly ripe (32 WAF).

The qualitative pattern of the UF constituents at different maturation periods (22, 25, and $32 \mathrm{WAF})$ was determined by gas chromatography-mass spectrometry (GC-MS) analysis ( $\bullet$ Table 1 ), allowing the detection of squalene, $\beta$-sitosterol, $\alpha$-tocopherol, lanosterol, and stigmasterol at all WAF tested. However, $\alpha$-amyrin,
Table 1 Qualitative and semi-quantitative GC-MS analysis of the UFs at the 22, 25, 32 WAF.

\begin{tabular}{|c|c|c|c|}
\hline \multirow[b]{2}{*}{ Unsaponifiable compound } & \multicolumn{3}{|c|}{ Relative percentage (\%) } \\
\hline & 22 WAF & 25 WAF & 32 WAF \\
\hline Squalene & 29.46 & 63.72 & 79.32 \\
\hline$\beta$-Sitosterol & 15.35 & 14.25 & 10.83 \\
\hline$\alpha$-Amyrin & 12.74 & n.d. & n.d. \\
\hline$\alpha$-Tocopherol & 12.24 & 8.82 & 2.67 \\
\hline$\beta$-Amyrin & 6.26 & n.d. & n.d. \\
\hline Lanosterol & 4.49 & 2.55 & 3.27 \\
\hline Stigmasterol & 3.28 & 2.86 & 2.73 \\
\hline Cycloartanol acetate & 2.99 & n.d. & n.d. \\
\hline Stigmastan-3,5-diene & 2.93 & n.d. & n.d. \\
\hline Obtusifoliol & 2.71 & n.d. & n.d. \\
\hline Cholesta-4,6-dien-3-one & 1.66 & n.d. & n.d. \\
\hline 9,19-Ciclolanost-7-en-3-ol & 1.41 & n.d. & n.d. \\
\hline Cholest-4-en-3-one & 1.37 & n.d. & n.d. \\
\hline minor compounds (<2\%) & 3.11 & 7.8 & 1.18 \\
\hline
\end{tabular}

Individual data are expressed as relative \% (calculated from the area under each peak) of the total pool area; $n=3$; S. D. $<10 \%$; n. d., not detected

$\beta$-amyrin, stigmastan-3,5-diene, obtusifoliol, cycloartanol acetate, cholesta-4,6-dien-3-one, 9,19-ciclolanost-7-en-3-ol, and cholest-4-en-3-one were detected only at $22 \mathrm{WAF}$, and not at 25 and $32 \mathrm{WAF}$, indicating consistent changes in bioactive constituents over the time of development. Interestingly, most of the constituents detected at 22 WAF have been proposed as early biosynthetic intermediates of the sterol pathway [8]. This analysis also gave semiquantitative indications on the relative percentage of each component ( $\bullet$ Table $\mathbf{1}$ ). For the quantitative analysis ( $\triangle$ Table 2) of each UF constituent at the 22, 25, and 32 WAF, a calibration curve was set. Among the compounds detectable at all time points, at $22 \mathrm{WAF}$, lanosterol was $2.60 \mathrm{mg} / \mathrm{g}$ oil and stigmasterol was $2.15 \mathrm{mg} / \mathrm{g}$ oil and both decreased to about $1 \mathrm{mg} / \mathrm{g}$ oil at 25 and 32 WAF. Moreover, squalene was $1.02 \mathrm{mg} / \mathrm{g}$ oil at $22 \mathrm{WAF}$, increased to $2.22 \mathrm{mg} / \mathrm{g}$ oil at $25 \mathrm{WAF}$ and then decreased to $1.38 \mathrm{mg} / \mathrm{g}$ oil at $32 \mathrm{WAF} ; \beta$-sitosterol was $0.22 \mathrm{mg} / \mathrm{g}$ oil and decreased to about $0.13 \mathrm{mg} / \mathrm{g}$ oil at 25 and $32 \mathrm{WAF}$; and $\alpha$-tocopherol was $1.32 \mathrm{mg} / \mathrm{g}$ oil and decreased to about $0.40 \mathrm{mg} / \mathrm{g}$ oil at 25 and 32 WAF. The drop in $\alpha$-tocopherol paralleled the decrease in the UF content of the oils from drupes at different harvesting times. This suggests that this antioxidant has some sort of protective action on the constituents of the unsaponifiable matter. In line with the qualitative data, we could detect $\alpha$-amyrin, $\beta$-amyrin, stigmastan-3,5-diene, obtusifoliol, cycloartanol acetate, and cholesta-4,6-dien-3-one only at $22 \mathrm{WAF}$, and not at 25 and 32 WAF.

The main physicochemical characteristics of oil from unripe olives (22 WAF) have also been evaluated [free acidity value expressed as oleic acid (1.043), low peroxide index (7.032), saponification value (184.46), and iodine value (76.329)], suggesting that it may be classified as extra virgin oil according to Eu.Ph. 7.0. To sum up, the UF from unripe oil (22 WAF) contains a bulk of molecules with potential pharmacological activity (anti-inflammatory, antioxidant) and, most important, present in a consistent amount.

The results of the pilot study on the efficacy of the ointment containing $5 \%$ of the bioactive UF ( $22 \mathrm{WAF}$ ) in the relief of active OA signs and symptoms are reported in $\odot$ Table 3 . The application (three times/day for three weeks) of the UF ointment resulted in a significant overall improvement of the clinical features in all $\mathrm{OA}$ 


\begin{tabular}{|c|c|c|c|c|c|c|}
\hline \multirow{4}{*}{$\begin{array}{l}\text { Unsaponifiable compound } \\
\text { Lanosterol }\end{array}$} & \multicolumn{6}{|c|}{ Quantitative analysis (mg/goil) } \\
\hline & \multirow{2}{*}{\multicolumn{2}{|c|}{$\begin{array}{l}22 \mathrm{WAF} \\
\text { mean } \pm \text { SD }\end{array}$}} & \multirow{2}{*}{\multicolumn{2}{|c|}{$\begin{array}{l}25 \mathrm{WAF} \\
\text { mean } \pm S D\end{array}$}} & \multirow{2}{*}{\multicolumn{2}{|c|}{$\begin{array}{l}32 \mathrm{WAF} \\
\text { mean } \pm S D\end{array}$}} \\
\hline & & & & & & \\
\hline & 2.60 & 0.12 & 1.02 & 0.08 & 0.97 & 0.07 \\
\hline Stigmasterol & 2.15 & 0.17 & 1.04 & 0.09 & 0.96 & 0.05 \\
\hline Cycloartanol acetate & 2.04 & 0.09 & n.d. & n.d. & n.d. & n.d. \\
\hline Stigmastan-3-5-diene & 2.01 & 0.06 & n.d. & n.d. & n.d. & n.d. \\
\hline Obtusifoliol & 1.93 & 0.06 & n.d. & n.d. & n.d. & n.d. \\
\hline Cholesta-4,6-dien-3-one & 1.42 & 0.03 & n.d. & n.d. & n.d. & n.d. \\
\hline$\alpha$-Amyrin & 1.42 & 0.04 & n.d. & n.d. & n.d. & n.d. \\
\hline$\alpha$-Tocopherol & 1.32 & 0.07 & 0.47 & 0.03 & 0.40 & 0,00 \\
\hline Squalene & 1.02 & 0.02 & 2.22 & 0.02 & 1.38 & 0.01 \\
\hline$\beta$-Amyrin & 0.57 & 0.01 & n.d. & n.d. & n.d. & n.d. \\
\hline$\beta$-Sitosterol & 0.22 & 0.01 & 0.14 & 0.02 & 0.13 & 0.02 \\
\hline
\end{tabular}

Table 2 Quantitative GC-MS analysis of the UF constituents at the 22,25 and 32 WAF.

( $n=3 ;$ n. d., not detected)

patients after two and three weeks of treatment. In particular, joint pain, as evaluated by the visual analogue scale, was reduced from 8.0 to 2.2 ( $p=0.02$ at three weeks). In addition, joint redness, heat, edema, and loss of mobility were also significantly improved. As expected, joint deformity was not affected at any time point. All subjects completed the study and experienced no adverse reactions.

\section{Discussion}

$\nabla$

This study evaluated the qualitative and quantitative composition of the UF present in the oil of unripe olives. The analytical data allowed us to depict very relevant variations in the phytochemical profile of the bioactive structures across drupe ontology, since the UF amount was greater at 22 WAF and decreased during fruit maturation. The main constituents of the $22 \mathrm{WAF}$ UF are triterpenes with anti-inflammatory properties. Thus, a detailed analytical investigation by GC-MS allowed us to identify the period (22 WAF) at which the oil obtained from drupes gives the major yield in anti-inflammatory UF constituents and showed us a picture of the different steps on the biosynthetic relationship between steroid and triterpenoid pathways throughout 0 . europaea fruit development. In contrast to what was observed by Sakouhi et al. [8], who worked on Meski olives and depicted a decline in squalene content between 21 and 26 WAF, we still observed a strong accumulation of squalene at 32 WAF (near the final time of maturation), which may be due to different factors, including environmental and climatic conditions, that may influence the kinetics of fruit development and the fruit cultivar. According to these observations, a detailed control of the composition of the bioactive constituents of unripe fruits, before the evaluation of their biological activities, appears mandatory. Moreover, we found the presence of elevated amounts of $\alpha$ - and $\beta$-amyrins until 22 WAF. Afterwards, there is a redirection of the carbon flux from the triterpenoid pathway to the steroid pathway, with elevated lanosterol and stigmasterol content at 22 WAF and a peak in squalene production at $25 \mathrm{WAF}$, in accordance with the findings of Stiti et al. [9].

The concept that oil from unripe olives possesses medicinal properties actually dates back to antiquity. The Romans called this oil Oleum Omphacium, and Dioscorides (ca. 40-90 AD) and Pliny the Elder (23-79 AD) mentioned that it was used as a vehicle for preserving perfumes and as a beneficial health food [10]. The potential anti-inflammatory activity of the UF from mature virgin olive
Table 3 Clinical effect of $5 \%$ bioactive UF (22 WAF) ointment on hand and knee osteoarthrosis symptoms and signs.

\begin{tabular}{|c|c|c|c|}
\hline & Time (week) & VAS evaluation & $\mathbf{p}$ \\
\hline \multirow[t]{4}{*}{ Pain } & 0 & $8.0 \pm 0.2$ & - \\
\hline & 1 & $5.2 \pm 1.1$ & 0.028 \\
\hline & 2 & $4.0 \pm 1.4$ & 0.019 \\
\hline & 3 & $2.2 \pm 1.1$ & 0.002 \\
\hline \multirow[t]{4}{*}{ Redness } & 0 & $3.0 \pm 0.2$ & - \\
\hline & 1 & $2.4 \pm 0.6$ & 0.423 \\
\hline & 2 & $1.6 \pm 0.6$ & 0.028 \\
\hline & 3 & $1.2 \pm 0.8$ & 0.050 \\
\hline \multirow[t]{4}{*}{ Heat } & 0 & $2.8 \pm 0.4$ & - \\
\hline & 1 & $2.0 \pm 0.7$ & 0.097 \\
\hline & 2 & $1.2 \pm 0.4$ & 0.017 \\
\hline & 3 & $0.8 \pm 0.4$ & 0.001 \\
\hline \multirow[t]{4}{*}{ Oedema } & 0 & $3.0 \pm 0.2$ & - \\
\hline & 1 & $2.0 \pm 0.2$ & 0.005 \\
\hline & 2 & $1.4 \pm 0.5$ & 0.017 \\
\hline & 3 & $0.6 \pm 0.5$ & 0.004 \\
\hline \multirow[t]{4}{*}{ Loss of mobility } & 0 & $3.4 \pm 0.5$ & - \\
\hline & 1 & $2.2 \pm 0.5$ & 0.023 \\
\hline & 2 & $1.8 \pm 0.8$ & 0.017 \\
\hline & 3 & $1.0 \pm 0.7$ & 0.004 \\
\hline \multirow[t]{4}{*}{ Joint deformity } & 0 & $1.4 \pm 0.5$ & n.s. \\
\hline & 1 & $1.4 \pm 0.5$ & n.s. \\
\hline & 2 & $1.4 \pm 0.5$ & n.s. \\
\hline & 3 & $1.4 \pm 0.5$ & n.s. \\
\hline
\end{tabular}

( $n=5$, mean $\pm S D$; one-way ANOVA repeated measures)

oil has previously been reported by Rocho de la Puerta et al. [11] in a study of mice, showing the anti-inflammatory action of the UF after topical application of the active material $(0.5 \mathrm{mg} /$ ear $)$ on auricular edema. In agreement with these observations, the results of the pilot study in OA patients indicate that the UF from the oil of unripe olives strongly attenuates the severity of active OA signs and symptoms when topically applied to inflamed joints. The ointment was designed to contain a high concentration of UF bioactive constituents, and the vehicle, due to the presence of essential oils and grade B shea butter, which are devoid of any biological activity, is, however, a strong enhancer of skin penetration of these bioactives. From a mechanistic viewpoint, the beneficial effects of the UF on OA may stem from an overall inhibitory action on well-distinct triggers of the inflammatory cascade. In particular: 1 ) phytosterols, such as $\beta$-sitosterol, which exert a strong anti-inflammatory action by inhibiting nuclear 
factor- $k \mathrm{~B}$ nuclear translocation [11], and interleukin-6 and tumor necrosis factor- $\alpha$ secretion $[12,13]$; 2) $\alpha-\beta$ amyrins, with both antinociceptive and anti-inflammatory activity [14,15]; 3) $\alpha$-tocopherol, which prevents the increase in prostaglandin E2 and thromboxane 2 in LPS-stimulated macrophages, partly through inhibition of cyclooxygenase and lipooxygenase translation and partly by directly scavenging free radicals $\bullet \mathrm{OH}$ and $\mathrm{NO} \cdot$ [16]; and 4) squalene is endowed with a strong scavenging activity [17] against superoxide anion and its metabolites. These preliminary clinical data in OA patients clearly need to be confirmed and validated by larger clinical trials with an appropriate design. Moreover, besides the efficacy of UF from the oil of unripe olives in attenuating OA symptoms, this oil, as such, may also be taken into consideration for the development of nutraceuticals for the prevention and treatment of other chronic diseases where the pathophysiological trigger is oxidative/inflammatory stress.

\section{Materials and Methods}

$\nabla$

\section{Plant material and analytical protocol}

The experiment took place during 2011 (pilot experiment) and was completed in 2012. Unripe drupes from the cultivar "Gentile" were hand-harvested weekly from the 20 WAF until complete maturity of the fruits (32 WAF). Olives without physical damage were selected from multiple trees of the same cultivar and prepared for the extraction step. Samples of olive fruits ( $300 \pm 10 \mathrm{~g}$ ) at different stages of development were ground using a laboratory scale hammer mill and the material quantitatively recovered was extracted with n-hexane using a Soxhlet apparatus (90 $\mathrm{min}$ ). The procedure was repeated three times and the organic extracts were collected, filtered on anhydrous sodium sulphate, and taken to dryness under reduced pressure at $20^{\circ} \mathrm{C}$ to give the oil fractions. These fractions were submitted to the saponification procedure [18] and the isolated UFs (gravimetrically determined), were quali/quantitatively analyzed by GC-MS [19]. Having established which stage of olive fruit maturation would give a UF containing the greatest amount of bioactive constituents, in the next year (2012) the drupes at the same stage of maturation were submitted to a conventional cold press method and the oil recovered was used, in part, for UF isolation after an analytical control of its composition and, in part, to check the physicochemical parameters routinely employed to define an extra virgin oil (Eu.Ph. 7.0, assay 2.5.1, 2.5.3, 2.5.4), i.e., free acidity, saponification, ester, peroxide, and iodine values.

\section{Reagents and standards}

All solvents and reagents were of analytical grade and purchased from Sigma-Aldrich: n-hexane, anhydrous sodium sulfate, methanol, ethanol, petroleum ether, potassium hydroxide, phenolphthalein, chloroform iodide, sodium thiosulfate, starch solution, Wijs solution (iodine monochloride with glacial acetic acid), and carbon tetrachloride. Gaseous hydrochloric acid ( $\mathrm{HClg}$ ) was from Sapio. Analytical standards $\alpha$-tocopherol (Eu.Ph. grade), $\alpha$-amyrin (HPLC purity $>98.5 \%$ ), $\beta$-amyrin (HPLC purity $>98 \%$ ), squalene (HPLC purity $>98 \%$ ), lanosterol (purity $>93 \%$ ), stigmasterol (purity $>95 \%$ ), cholesta-4,6-dien-3-one (HPLC purity $>98 \%$ ), $\beta$-sitosterol (HPLC purity $>97 \%$ ), and cholesterol (Sigma grade purity $>99 \%$ ) were purchased from Sigma-Aldrich. Cycloartanol acetate (HPLC purity $>90 \%$ ) was purchased from Extrasynthese. Obtusifoliol (HPLC purity > 99\%) was from Gamay Industrial Technology Co. and stigmastan-3-5-diene (HPLC purity >98\%) was from
Apollo Scientific, Inc. Gravimetric determination was done using a precision balance from GIBERTINI ${ }^{\circledR}$ (E50 S model). Grade B (refined) shea butter and beeswax were from I.R.A. and essential oils were from Aroma-zone.

\section{Sample preparation and unsaponifiable}

fraction extraction

The fruits samples ( $5.00 \pm 0.10 \mathrm{~g}$ ), collected at the different weeks of maturation, were submitted to a grinding procedure and the homogenate was extracted under vigorous stirring $(\mathrm{T}=1 \mathrm{~h})$ three times at room temperature with $25 \mathrm{~mL}$ of n-hexane. The organic fractions, dried over anhydrous sodium sulphate $(10 \% \mathrm{w} / \mathrm{v})$, were collected and taken to dryness under vacuum. The oil fraction obtained was submitted to the saponification procedure as described [18]. Briefly, the oil sample was saponified under reflux with $50 \mathrm{~mL}$ of $\mathrm{H}_{2} \mathrm{O}$ saturated with $\mathrm{KOH}(\mathrm{t}=4 \mathrm{~h})$. The UF was extracted with $100 \mathrm{~mL}$ of $\mathrm{n}$-hexane $(\mathrm{n}=3)$ and the organic phases were collected and taken to dryness under vacuum, and the UF yield was gravimetrically determined. The UFs from oils at different stages of maturation were submitted to GC-MS analysis to profile the bioactive constituents.

\section{Gas chromatography-mass spectrometry analysis}

The UFs from the oils of olives at different stages of maturation were analyzed by GC-MS using a Bruker Scion SQ instrument equipped with a Factor Four capillary column (VF-5 ms, 30 m; $0.25 \mathrm{~mm}$ i.d., film thickness $0.25 \mu \mathrm{m}$ ) coupled with a singlequadrupole (SQ) detector. The oven temperature was initially set at $60{ }^{\circ} \mathrm{C}$ (hold time $3 \mathrm{~min}$ ), with a gradient from 60 to $120^{\circ} \mathrm{C}\left(8^{\circ} \mathrm{C} /\right.$ min, hold $1 \mathrm{~min})$, from 120 to $280^{\circ} \mathrm{C}\left(4^{\circ} \mathrm{C} / \mathrm{min}\right.$, hold $\left.1 \mathrm{~min}\right)$, and from 280 to $300^{\circ} \mathrm{C}\left(10^{\circ} \mathrm{C} / \mathrm{min}\right.$, hold $\left.2.5 \mathrm{~min}\right)$; injector temperature $250^{\circ} \mathrm{C}$, hold $95 \mathrm{~min}$, column flow $1 \mathrm{~mL} / \mathrm{min}$. The carrier gas was helium 5.5, ionization energy $70 \mathrm{eV}$, and the split/splitless ratio was set at $1: 30$ after $45 \mathrm{~s}$. Twenty mg of the UF samples were derivatized with $450 \mu \mathrm{L}$ of $\mathrm{MeOH}$ saturated with gaseous $\mathrm{HCl}$ and left to react for $40 \mathrm{~min}$ at $42^{\circ} \mathrm{C}$. The mixture was then exhaustively extracted with $600 \mu \mathrm{L}$ of $n$-hexane $(n=3)$, and $1 \mu \mathrm{L}$ of the extract was analyzed by GC-FID and characterized by GC-MS. Peak identification was performed by retention index analysis and confirmed by matching their mass spectra with those of the commercial library NIST mass spectral database $(2.0,2011)$ or, when necessary, confirmed with commercial standards. Each peak was allowed to identify a specific compound and the area under the peak allowed to semiquantitatively estimate the amount of this structure. Individual data are expressed as relative $\%$ of the total pool area. In particular, for the GC-MS quantitative analysis of triterpenols and sterols, a calibration curve for each compound was set, and the limit of detection, lower limit of quantification, and linearity range were evaluated ( $\bullet$ Table 4 ). In order to define the recovery of the method for the UF extraction, $500 \mu \mathrm{g}$ of cholesterol were added to $100 \mu \mathrm{L}$ of olive oil and submitted to methylation with $450 \mu \mathrm{L}$ of $\mathrm{MeOH}$ saturated with gaseous $\mathrm{HCl}$, as described. The mixture was extracted with $800 \mu \mathrm{L}$ of n-hexane, and $1 \mu \mathrm{L}$ of the organic phase was submitted to GC-MS analysis (625 theoretical ng of cholesterol was injected). The obtained peak area was compared with the area from the same quantity of cholesterol diluted in n-hexane $(625 \mathrm{ng} / \mu \mathrm{L})$. The mean \% of extraction recovery was $98.22 \pm 2.73(n=3)$. 
Table 4 GC-MS quantitative analysis of triterpenols and sterols.

\begin{tabular}{|lllll|}
\hline Unsaponifiable compound & LOD (ng) & LLOQ (ng) & Linearity range (ng) & $\mathbf{R}^{\mathbf{2}}$ \\
\hline Squalene & 25.7 & 42.9 & $42.9-858$ & 0.997 \\
\hline$\beta$-Sitosterol & 30.7 & 51.2 & $51.25-820$ & 0.999 \\
\hline$\alpha$-Amyrin & 21 & 35 & $35-350$ & 0.992 \\
\hline$\alpha$-Tocopherol & 22.0 & 36.7 & $36.7-7340$ & 0.993 \\
\hline$\beta$-Amyrin & 21 & 35 & $35-350$ & 0.994 \\
\hline Lanosterol & 37.2 & 62 & $62-2480$ & 0.991 \\
\hline Stigmasterol & 34.8 & 58 & $58-5800$ & 0.991 \\
\hline Cycloartanol acetate & 18 & 30 & $30-1650$ & 0.991 \\
\hline Stigmastan-3,5-diene & 19.2 & 32 & $32-3200$ & 0.994 \\
\hline Obtusifoliol & 27 & 45 & $45-4500$ & 0.994 \\
\hline Cholesta-4,6-dien-3-one & 20.4 & 34 & $34-850$ & 0.999 \\
\hline 9,19-Ciclolanost-7-en-3-ol & 14.4 & 24 & $24-820$ & 0.997 \\
\hline Cholest-4-en-3-one & 16.8 & 28 & $28-560$ & 0.997 \\
\hline Cholesterol extraction recovery & $\mathbf{6 2 5} \mathbf{n g}$ inj std area & $\mathbf{6 2 5} \mathbf{n g}$ inj extr area & Recovery \% & Mean \\
\hline & 190800000 & 189000000 & 99.1 & 98.2 \\
\hline
\end{tabular}

\section{Statistical analysis of the analytical data}

All of the analyses were carried out in triplicate. The results are expressed as mean values and standard deviation (SD), and were analyzed using one-way analysis of variance (ANOVA), followed by Tukey's HSD test (SPSS v 16.0 program).

\section{Ointment preparation}

The ointment contained, as the active component, UF ( $5 \% \mathrm{w} / \mathrm{w})$ from the oil of unripe olives (22 WAF). The vehicle was constituted by extra virgin olive oil ( $54 \%$ ), beeswax ( $32 \%$ ), grade B (i.e., refined and thus not containing unsaponifiable structures) shea butter (14\%), perfumes (essential oils of mint $0.80 \%$ and lavender $0.60 \%$ ), and preservatives (essential oils of rosemary $0.40 \%$ and tea tree $0.20 \%$, also added as a skin enhancer). The GC-MS analysis of this vehicle ( $\boldsymbol{O}$ Fig. $\mathbf{2}$ ) showed a predominance of fatty acids (86.49\%) and paraffins (12.18\%), followed by small amounts of terpenes $(0.98 \%)$. To the best of our knowledge, none of these structures has been shown to exhibit anti-inflammatory activity in humans. The ointment was examined by routine cosmetic tests for physical and chemical stability, kindly run by the Istituto di Ricerche Applicate.

\section{Pilot clinical study}

Five outpatient volunteers (two men and three women, mean age $60.2 \pm 8.1$ years) with symptomatic (hand joints/knees pain) OA diagnosed 2-5 years prior participated in the study, which was conducted in accordance with the guidelines of the Declaration of Helsinki, and the study protocol was approved by the Institutional Ethics Committee (date of approval: July 27, 2012; approval number: 296_07/2012). Written informed consent was obtained from each subject. They were asked to avoid any pharmacological treatment starting from three weeks before the beginning of the study (run-in period) and during the three weeks of the topical application of the UF ointment. Volunteers were instructed on a self-application of $5 \mathrm{~g} /$ application (three times/daily) of the ointment on the painful joints of the knees and hands until complete absorption. It was recommended they keep strictly to their usual eating habits and avoid any functional foods that might influence the inflammatory joint disease. All the volunteers were examined by the same physician at the beginning of the study and at weekly intervals until completion of the treat-

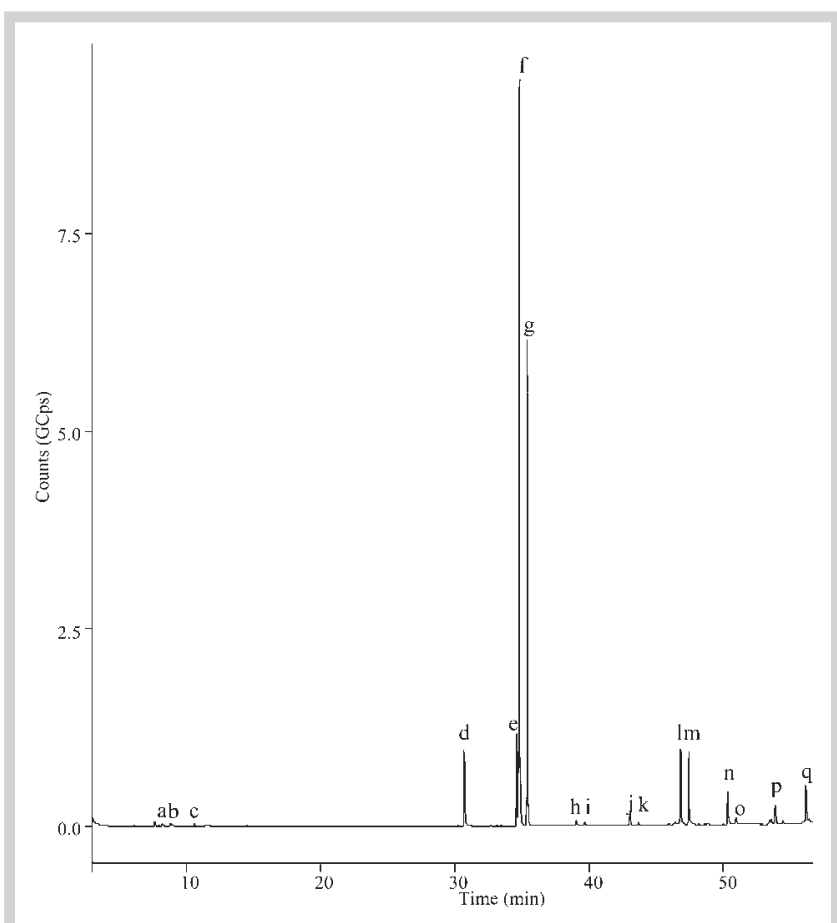

Fig. 2 GC-MS analysis of the ointment vehicle. A representative GC-MS chromatogram shows the ointment vehicle constituents, which are mainly fatty acids and paraffins (a: eucalyptol; b: $\gamma$-terpinene; c: terpinen-4-ol; d: palmitic acid; e: linoleic acid; f: oleic acid; g: stearic acid; $\mathrm{h}$ : $\mathrm{n}$-tetracosane; i: arachidic acid; j: n-heptacosane; k: docosanoic acid; I: n-hentriacontane; m: lignoceric acid; n: hexatriacontane; o: cerotic acid; p: tetratertacontane; $\mathrm{q}: \mathrm{n}$-octacosanol).

ment protocol. The effects of UF on joint pain were assessed weekly using the visual analogue scale [20]. The signs and symptoms of inflammation (joint redness, heat, tissue swelling, loss of mobility, and joint deformity) were recorded by visual inspection and physical examination by a physician. The remission of objective symptoms was expressed using an arbitrary numerical scale from 0 (best) to 4 (worst). All the volunteers completed the study 
and none experienced any skin irritation or cutaneous allergic reactions after application of the UF ointment.

\section{Statistical analysis of the pilot clinical outcomes}

The effect of UF ointment treatment on different variables was assessed by one-way ANOVA for repeated measures. Normality was assessed by the Kolmogorov-Smirnov test. Continuous variables are indicated as mean $\pm S D$. Significant differences were considered when $\mathrm{p}$ value $\leq 0.05$. Statistical analysis was performed by using the SPSS package version 20.0.

\section{Conflict of Interest}

The authors state that there are no conflicts of interest related with the present manuscript.

\section{References}

1 Reziga L, Chouaibia M, Msaadab K, Hamdi S. Chemical composition and profile characterisation of pumpkin (Cucurbita maxima) seed oil. Ind Crop Prod 2012; 37: 82-87

2 Sakouhia F, Absalonb C, Harrabia S, Vitryb C, Sebeia K, Boukhchinaa S, Fouquetb E, Kallela $\mathrm{H}$. Dynamic accumulation of 4-desmethylsterols and phytostanols during ripening of Tunisian Meski olives (Olea europea L.). Food Chem 2009; 112: 897-902

3 Pasceri V, Yeh ET. A tale of two diseases: atherosclerosis and rheumatoid arthritis. Circulation 1999; 100: 2124-2126

4 Marks WH. Tripterygium wilfordii Hook F. versus sulfasalazine in the treatment of rheumatoid arthritis: a well-designed clinical trial of a botanical demonstrating effectiveness. Fitoterapia 2011; 82: 85-87

5 Burgos RA, Hancke JL, Bertoglio JC, Aguirre V, Arriagada S, Calvo M, Caceres DD. Efficacy of an Andrographis paniculata composition for the relief of rheumatoid arthritis symptoms: a prospective randomized placebo-controlled trial. Clin Rheumatol 2009; 28: 931-946

6 Bony E, Boudard F, Dussossoy E, Portet K, Brat P, Giaimis J, Michel A. Chemical composition and anti-inflammatory properties of the unsaponifiable fraction from awara (Astrocaryum vulgare M.) pulp oil in activated J774 macrophages and in a mice model of endotoxic shock. Plant Foods Hum Nutr 2012; 67: 384-392

7 Montserrat-de la Paz S, Fernandez-Arche A, Angel-Martin M, Garcia-Gimenez MD. The sterols isolated from Evening Primrose oil modulate the release of proinflammatory mediators. Phytomedicine 2012; 19: 1072-1076

8 Sakouhi F, Herchi W, Sbei K, Absalon C, Boukhchina S. Characterisation and accumulation of squalene and n-alkanes in developing Tunisian Olea europaea L. fruits. Int J Food Sci Tech 2011; 46: 2281-2286

9 Stiti N, Triki S, Hartmann MA. Formation of triterpenoids throughout Olea europaea fruit ontogeny. Lipids 2007; 42: 55-67

10 Castel C, Fernandez X, Filippi JJ, Brun JP. Perfumes in Mediterranean antiquity. Flavour Frag J 2009; 24: 326-334

11 de la Puerta R, Martinez-Dominguez E, Ruiz-Gutierrez V. Effect of minor components of virgin olive oil on topical antiinflammatory assays. Z Naturforsch C 2000; 55: 814-819

12 Loizou S, Lekakis I, Chrousos GP, Moutsatsou P. Beta-sitosterol exhibits anti-inflammatory activity in human aortic endothelial cells. Mol Nutr Food Res 2009; 54: 551-558

$13 \mathrm{Al}$-Okbi SY. Nutraceuticals of anti-inflammatory activity as complementary therapy for rheumatoid arthritis. Toxicol Ind Health 2012; 30: 738-749

14 Magni P, Ruscica M, Dozio E, Rizzi E, Beretta G, Maffei Facino R. Parthenolide inhibits the LPS-induced secretion of IL- 6 and TNF- $\alpha$ and NFkB nuclear translocation in BV-2 microglia. Phytother Res 2012; 26: 1405-1409

15 Holanda Pinto SA, Pinto LM, Guedes MA, Cunha GM, Chaves MH, Santos FA, Rao VS. Antinoceptive effect of triterpenoid alpha,beta-amyrin in rats on orofacial pain induced by formalin and capsaicin. Phytomedicine 2008; 15: 630-634

16 Melo CM, Morais TC, Tome AR, Brito GA, Chaves MH, Rao VS, Santos FA. Anti-inflammatory effect of $\alpha, \beta$-amyrin, a triterpene from Protium heptaphyllum, on cerulein-induced acute pancreatitis in mice. Inflamm Res 2011; 60: 673-681

17 Perona JS, Cabello-Moruno R, Ruiz-Gutierrez V. The role of virgin olive oil components in the modulation of endothelial function. J Nutr Biochem 2006: 17: 429-445

18 Reddy LH, Couvreur P. Squalene: A natural triterpene for use in disease management and therapy. Adv Drug Deliv Rev 2009; 61: 1412-1426

19 Gelmini F, Beretta G, Anselmi C, Centini M, Magni P, Ruscica M, Cavalchini A, Maffei Facino R. GC-MS profiling of the phytochemical constituents of the oleoresin from Copaifera langsdorffii Desf. and a preliminary in vivo evaluation of its antipsoriatic effect. Int J Pharm 2013; 440: 170178

20 Cohen $M$, Wolfe R, Mai T, Lewis D. A randomized, double blind, placebo controlled trial of a topical cream containing glucosamine sulfate, chondroitin sulfate, and camphor for osteoarthritis of the knee. J Rheumatol 2003; 30: 523-528 